\title{
Hepatic stellate cells transmigration and remodeling are related to CCN3 in oxaliplatin-resistant hepatocellular carcinoma
}

\author{
Ruitao Wang ${ }^{1}$, Wei Cheng ${ }^{2}$, Zhen Wang ${ }^{2}$, Qiangbo Zhang ${ }^{3}$, Yang $\mathrm{Bu}^{4}$, Songning $\mathrm{Yu}^{4}$ \\ and Qingan Jia ${ }^{1}$ \\ ${ }^{1}$ Department of Hepatobiliary Surgery, First Affiliated Hospital of Xi'an Jiaotong University, Xi'an 710061, China \\ ${ }^{2}$ Department of Cell Biology and Genetics, School of Basic Medical Sciences, Xi'an Jiaotong University Health Center, Xi'an \\ 710061, China \\ ${ }^{3}$ Department of General Surgery, Qilu Hospital, Shandong University, Jinan 250012, China \\ ${ }^{4}$ Department of Hepatobiliary Surgery, General Hospital, Ningxia Medical University, Yinchuan 750001, China \\ Correspondence to: Qingan Jia, email: qajia66@163.com
}

Keywords: hepatocellular carcinoma; CCN3; hepatic stellate cells; microenvironment; oxaliplatin resistance

Received: October 31, $2017 \quad$ Accepted: December 05, $2017 \quad$ Published: January 13, 2018

Copyright: Wang et al. This is an open-access article distributed under the terms of the Creative Commons Attribution License 3.0 (CC BY 3.0), which permits unrestricted use, distribution, and reproduction in any medium, provided the original author and source are credited.

\section{ABSTRACT}

Background: Hepatic stellate cells (HSCs) have a key role in fibrogenesis and in the filtrates of the hepatocellular carcinoma (HCC) stroma, in which they are remodeled and play a critical role in HCC progression. While, the precise mechanism associated with HSCs trending, infiltration and remodeling is still vague in $\mathrm{HCC}$, especially in Oxaliplatin-resistant HCC.

Materials and Methods: The chemoresistant cell and mouse model, and the HCC clinical samples were collected and were established. We explored the relationship between secretory CCN3 from Oxaliplatin-resistant HCC and the infiltration of HSCs in Oxaliplatin-resistant HCC microenvironment. We also evaluated the associated mechanism of HSCs infiltration and HSCs remodeling in HCC with high expression of CCN3.

Results: We constructed oxaliplatin-resistant HCC models and found the increased infiltration of HSCs into the microenvironment. We reanalyzed the cDNA profiles of the oxaliplatin-resistant HCC and found CCN3 was one of the significantly increased genes. In HCC clinical samples, the levels of CCN3 and a-SMA are positively correlated, and high expression of CCN3 and a-SMA are positively associated with malignant phenotype and poor prognosis. Then we proved that $\mathrm{CCN} 3$ could enhance the migration and proliferation of HSC, and induce the remodeling of HSC with elevation of cytokines relating to HCC malignancy, which was related to ERK signaling pathway activation. Finally, we confirmed that the role of CCN3 enhanced the transmigration of HSCs using the xenograft tumor model.

Conclusions: HSCs transmigration and remodeling are positively related to CCN3 paracrine in hepatocellular carcinoma, which orchestrated the stroma-derived resistance to chemotherapy in HCC.

\section{INTRODUCTION}

Primary liver cancer is the second leading cause of cancer death worldwide, with China alone accounting for about $50 \%$ of the total number of cases and deaths, and $80 \%$ primary liver cancers occurring worldwide are hepatocellular carcinoma (HCC) [1]. HCC occurs in a large percentage of cases during the clinical course of chronic infection by hepatitis $\mathrm{B}$ virus and hepatitis $\mathrm{C}$ virus leading to cirrhosis. Hepatic stellate cells (HSCs) have a key role in fibrogenesis and in filtrates of the HCC stroma, in which they are remodeled and enhance HCC malignant progression. While, the precise mechanism associated with HSCs trending, infiltration and remodeling are still vague in HCC, which orchestrated the stroma-derived resistance to oxaliplatin in $\mathrm{HCC}$ [2]. 
CCN3 (Nephroblastoma Overexpressed proteins, NOV) is one of the six-member family of cysteine-rich secretory proteins found in humans that emerged as localized multitasking signal integrators in the microenvironment, and play an important role in modifying the cellular phenotype [3]. Thus far, the expression of $\mathrm{CCN} 3$ in $\mathrm{HCC}$, and the precise physiological function and mechanism of action of $\mathrm{CCN} 3$ remain elusive. By cDNA microarrays, we found oxaliplatinresistant $\mathrm{HCC}$ exhibited the increased expression of $\mathrm{CCN} 3$ previously [4]. CCN3 as one of the secreted protein family sharing an N-terminal secretory signal domain followed by four conserved multifunctional domains, and the most ubiquitous function of the $\mathrm{CCN} 3$ is its ability to orchestrate the inflammatory microenvironment [5]. So, it is important to explore the role and mechanism of CCN3 paracrined by $\mathrm{HCC}$ in the transmigration and remodeling of HSCs in HCC microenvironment.

Through collecting HCC clinical samples and establishing chemoresistant cell and mouse model, we explored the relationship between secretory $\mathrm{CCN} 3$ from $\mathrm{HCC}$ and the infiltration of HSCs in HCC microenvironment. We also evaluated the associated mechanism of HSC infiltration and remodeling in $\mathrm{HCC}$ with high expression of $\mathrm{CCN} 3$. In this study, our findings suggested that $\mathrm{CCN} 3$ is a potential therapeutic target affecting the microenvironment with fibrosis, which may lead to an enhanced capacity of oxaliplatin-resistance in HCC.

\section{RESULTS}

\section{Infiltration of HSC are increased in the microenvironment of oxaliplatin-resistant HCC}

To explore the mechanism of oxaliplatin resistance from the perspective of tumor microenvironment, immunohistochemical staining revealed the increased expression of $\alpha$-SMA in HCC tissue from oxaliplatintreated tumor mice in the same trend with the enhanced resistance to chemotherapy (Figure 1A). Masson and Sirius staining also showed increased fibrous connective tissue and collagen accumulation in oxaliplatin-resistant HCC tissue (Figure 1A). In vitro, we collected the CM of oxaliplatin-resistant HCC cell line MHCC97H-OXA and the associated wide type MHCC97H-CON, and proved the enhanced migration ability of LX2 in the CM of MHCC97H-OXA than in the CM of MHCC $97 \mathrm{H}-\mathrm{CON}$ ( $31.60 \pm 7.16$ vs. $10.60 \pm 5.45 p=0.0081$ ) (Figure 1B). In this section, we proved the number of HSC are increased in the microenvironment of oxaliplatin-resistant HCC.

\section{Expression of CCN3 is upregulated in oxaliplatin-resistant HCC}

Previously, we constructed oxaliplatin-resistant HCC models and found the expression profiles for 332 genes had 2-fold differences in the oxaliplatin-resistant HCC using cDNA microarrays [4]. We reanalyzed the expression profiles and found CCN3 was one of the significantly changed genes in oxaliplatin-resistant HCC (Figure 2A). In the present study, the increased resistance was re-verified in MHCC $97 \mathrm{H}-\mathrm{OXA}(84.42 \pm 8.26 \mathrm{mmol} / \mathrm{l}$ vs. $27.67 \pm 5.37 \mathrm{mmol} / \mathrm{l}, p=0.0002)$ and Hep3B-OXA $(10.76 \pm 2.36 \mathrm{mmol} / \mathrm{l}$ vs. $3.86 \pm 0.68 \mathrm{mmol} / \mathrm{l}, P=0.0082)$ cells to oxaliplatin over that of wide type cells with the higher concentration of IC50 (Figure 2B). PCR (3.58 \pm 0.52 vs. $1.79 \pm 0.39, p=0.0072$, Figure $2 \mathrm{C}$ ) revealed that the gene expression of CCN3 in MHCC97H-OXA cells was increased significantly, compared with that of parental MHCC97H cells. ELISA $(78.83 \pm 25.76 \mathrm{ng} /$ $\mathrm{ml}$ vs. $17.69 \pm 12.65 \mathrm{ng} / \mathrm{ml}, p=0.036$, Figure $2 \mathrm{D}$ ), Immunoblotting (Figure 2E) and Immunofluorescence (Figure 2F) revealed that the expression of $\mathrm{CCN} 3$ in MHCC 97H-OXA cells was significantly higher than that of the parental MHCC97H cells. In addition, immunohistochemical staining revealed the proportion of CCN3 expression was significantly up-regulated in oxaliplatin-resistant HCC subcutaneous tissue (Figure $2 \mathrm{G})$. After reanalysis of oxaliplatin-resistant HCC models, we proved expression of $\mathrm{CCN} 3$ is upregulated in oxaliplatin-resistant HCC, which may be the cause of increased infiltration of HSC after treated by oxaliplatin.

\section{The high expression of CCN3 and $\alpha$-SMA are positively associated with malignant phenotype and poor prognosis in $\mathrm{HCC}$}

To illustrate the roles and the relationship of CCN3 and $\alpha$-SMA in HCC, we used tissue microarrays with 86 clinical samples and found a positive correlation between CCN3 and $\alpha$-SMA (Pearson 0.238, $p=0.027$ Figure $3 \mathrm{~A})$. And the expression of $\alpha$-SMA in high CCN3 HCC group was higher than $\alpha$-SMA in low CCN3 HCC group $(24.61 \pm 8.65$ vs. $18.09 \pm 11.42, p=0.0014$ Figure $3 \mathrm{~A})$. The HCC was also evaluated in mRNA level in another 98 clinical samples, and we also evaluated the relationship between CCN3 and $\alpha$-SMA, and found a positive correlation between CCN3 and $\alpha$-SMA (Pearson 0.46, $p$ $<0.001$ Figure 3B).

The expression of CCN3 and $\alpha$-SMA was also significantly associated with both OS and CRR. The patients in the CCN3-high group had significantly lower OS $(p=0.006)$ and higher CRR $(p<0.001)$ than patients in the CCN3-low group. The patients in the $\alpha$-SMA-high group also had significantly lower OS $(p=0.018)$ and higher CRR $(p=0.041)$ than patients in the CCN3-low group. Next, we classified the patients into three subgroups based on CCN 3 and $\alpha$-SMA expression levels. Group I had low expression of both CCN3 and $\alpha$-SMA, while Group II had high expression of either CCN3 or $\alpha$-SMA, and Group III had high expression of both CCN3 and $\alpha$-SMA. Group I had the best prognosis in the three groups, while 
OS $(p=0.208)$ and CRR $(p=0.126)$ in Group I was not significantly higher than that of patients in Group II. Also in Group I, the OS ( $p=0.001)$ was significantly higher and the CRR ( $p=0.001)$ was lower than in Group III. In Group II, the OS ( $p=0.01)$ was significantly higher and the CRR $(p=0.035)$ was significantly lower than in Group III (Figure 3C).

Furthermore, Cox regression analysis revealed a significant association of CCN3-high expression in tumor tissue with tumor dimension $(p=0.013)$, vascular invasion $(p=0.023)$, and tumor encapsulation $(p=0.014)$ of HCC. In regards to $\alpha$-SMA-high expression in tumor tissue, we found a significant correlation with tumor dimension ( $p=$ $0.044)$, and tumor encapsulation $(p=0.009)$ of HCC. No statistically significant association was found with other clinical characteristics (Table 1). In this section, we proved the expression levels of CCN3 and $\alpha$-SMA are positively correlated, and the high expression of CCN3 and $\alpha$-SMA
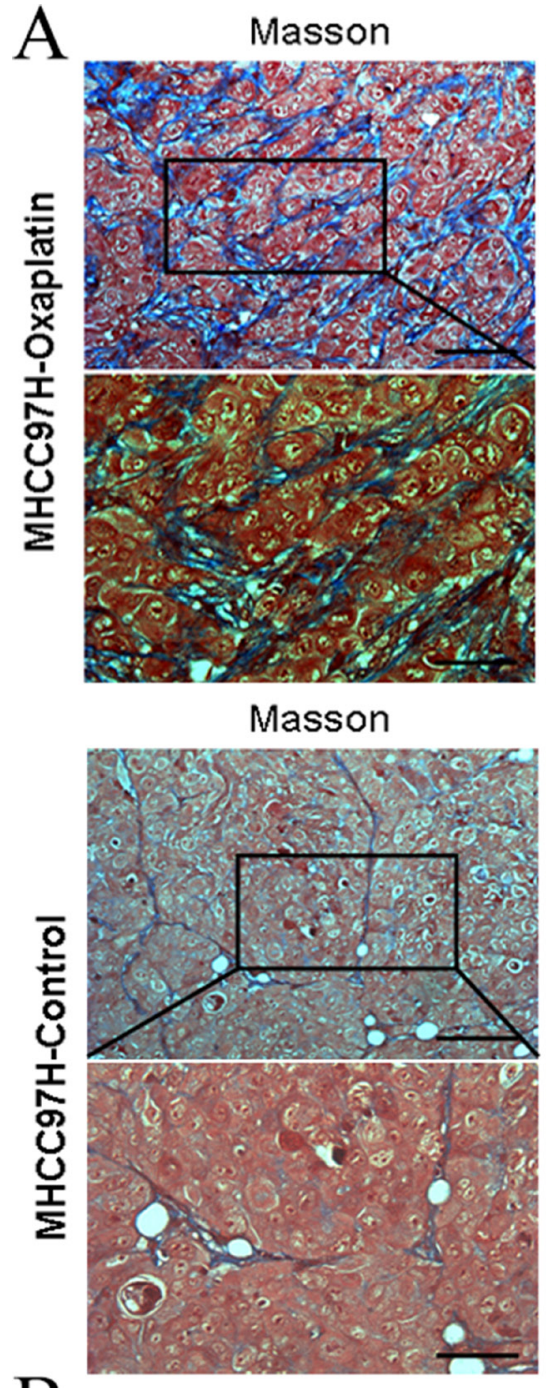

B

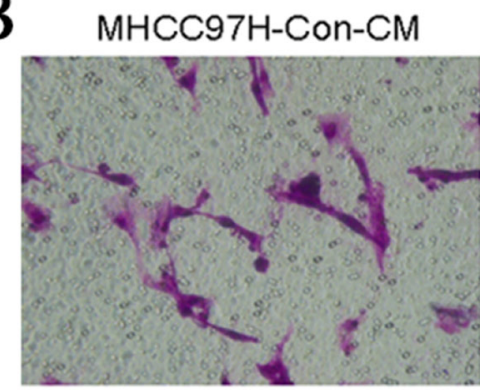

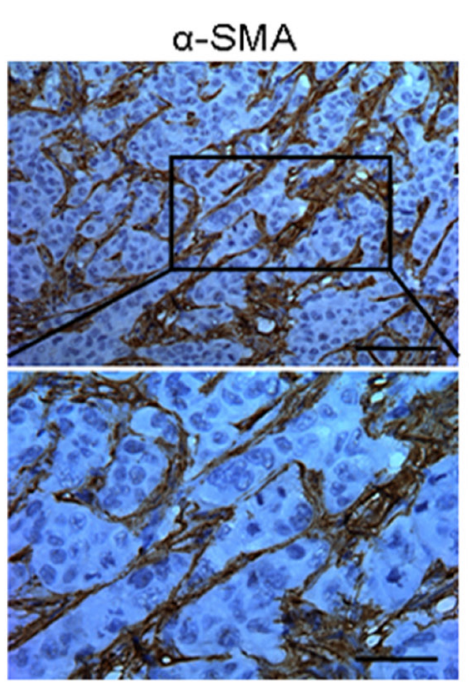

$\alpha-S M A$

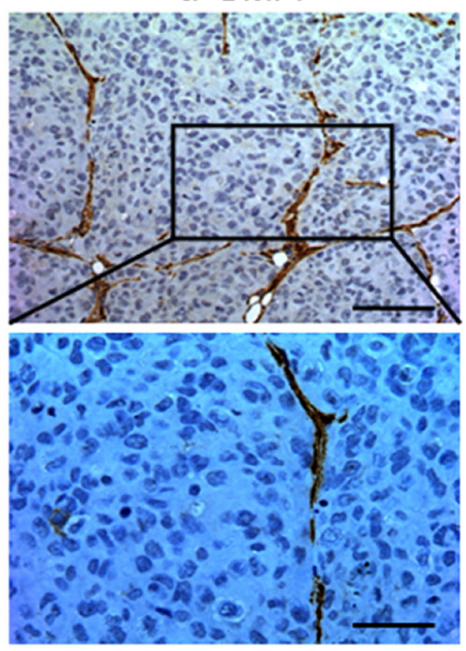

MHCC97H-Oxa-CM

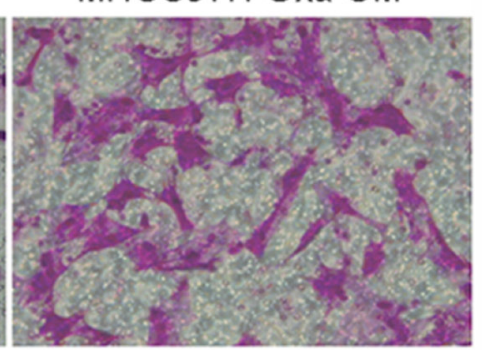

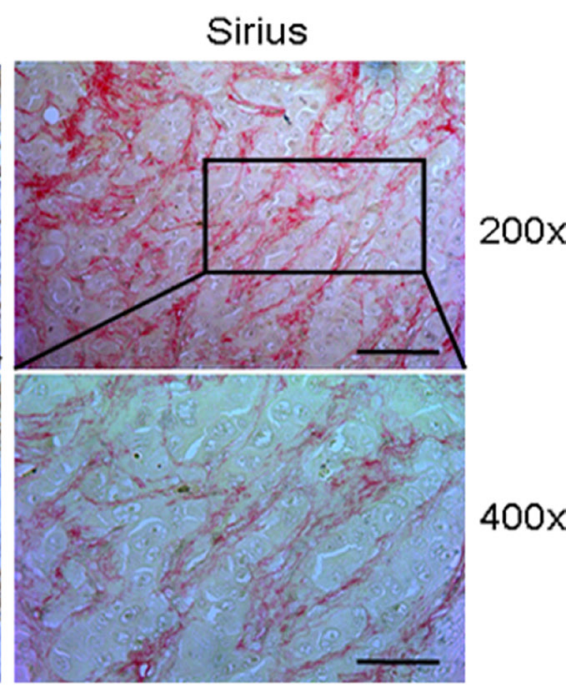
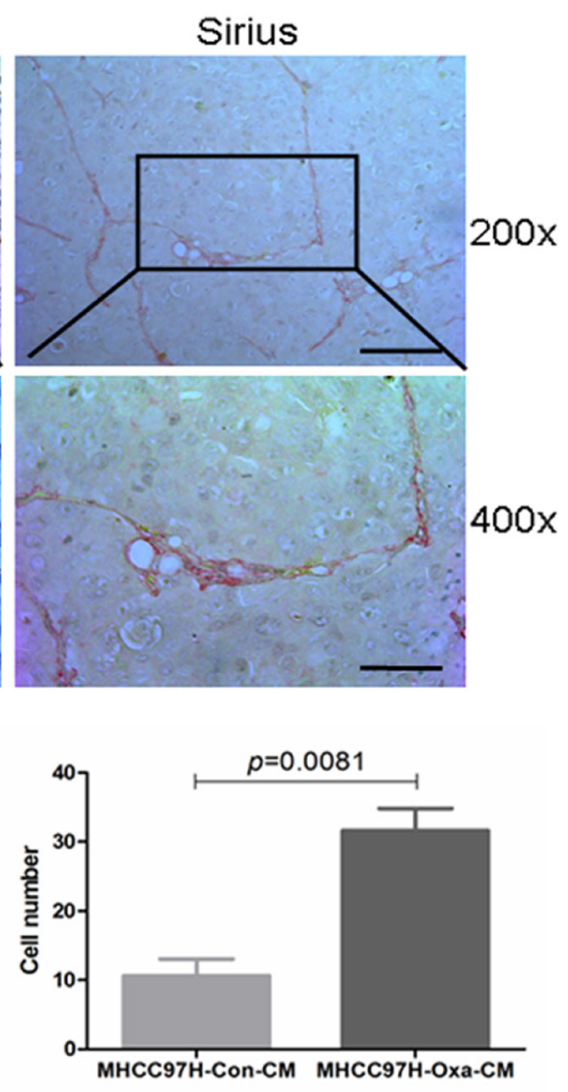

Figure 1: Infiltration of HSC increased in the microenvironment of oxaliplatin-resistant HCC. IHC. Masson and Sirius staining revealed the increased expression of fibrous connective tissue and collagen accumulation in oxaliplatin-resistant HCC tissue (A). The migration ability of LX2 was higher in the CM of oxaliplatin-resistant HCC than in the CM of wide type HCC (B). 
Table 1: Correlations between CCN3/SMA and clinicopathology feature in 86 patients with $\mathrm{HCC}$

\begin{tabular}{|c|c|c|c|c|c|c|}
\hline \multirow[b]{2}{*}{ Variable } & \multicolumn{2}{|c|}{ No. of Patient } & \multirow[b]{2}{*}{$p$} & \multicolumn{2}{|c|}{ No. of Patient } & \multirow[b]{2}{*}{$p$} \\
\hline & $\mathrm{CCN}^{\text {high }}$ & $\mathrm{CCN}^{\text {low }}$ & & SMA ${ }^{\text {high }}$ & SMA $^{\text {low }}$ & \\
\hline $\begin{array}{r}\text { Age, } y \\
\geq 53 \\
<53\end{array}$ & $\begin{array}{l}14 \\
19\end{array}$ & $\begin{array}{l}25 \\
28\end{array}$ & 0.419 & $\begin{array}{l}18 \\
26\end{array}$ & $\begin{array}{l}21 \\
21\end{array}$ & 0.397 \\
\hline $\begin{array}{l}\text { Sex } \\
\quad \text { Men } \\
\text { Women }\end{array}$ & $\begin{array}{c}26 \\
7\end{array}$ & $\begin{array}{c}44 \\
9\end{array}$ & 0.624 & $\begin{array}{c}36 \\
8\end{array}$ & $\begin{array}{c}34 \\
8\end{array}$ & 0.918 \\
\hline $\begin{array}{l}\text { HBsAg } \\
\text { Positive } \\
\text { Negative }\end{array}$ & $\begin{array}{c}30 \\
3\end{array}$ & $\begin{array}{c}48 \\
5\end{array}$ & $0.958^{*}$ & $\begin{array}{c}39 \\
5\end{array}$ & $\begin{array}{c}39 \\
3\end{array}$ & $0.501^{*}$ \\
\hline $\begin{array}{c}\text { Cirrhosis } \\
\text { Yes } \\
\text { No }\end{array}$ & $\begin{array}{c}29 \\
4\end{array}$ & $\begin{array}{c}46 \\
7\end{array}$ & $0.883^{*}$ & $\begin{array}{c}42 \\
2\end{array}$ & $\begin{array}{c}34 \\
9\end{array}$ & $0.085^{*}$ \\
\hline $\begin{array}{l}\text { Serum, AFP } \\
\quad \geq 20 \\
\quad<20\end{array}$ & $\begin{array}{l}21 \\
12\end{array}$ & $\begin{array}{l}32 \\
21\end{array}$ & 0.762 & $\begin{array}{l}29 \\
15\end{array}$ & $\begin{array}{l}24 \\
18\end{array}$ & 0.403 \\
\hline $\begin{array}{l}\text { Serum, ALT } \\
\quad \geq 75 \\
\quad<75\end{array}$ & $\begin{array}{l}11 \\
22\end{array}$ & $\begin{array}{l}27 \\
26\end{array}$ & 0.110 & $\begin{array}{l}15 \\
29\end{array}$ & $\begin{array}{l}23 \\
19\end{array}$ & 0.053 \\
\hline $\begin{array}{l}\text { Tumor dimen } \\
\quad \geq 5 \mathrm{~cm} \\
\quad<5 \mathrm{~cm}\end{array}$ & $\begin{array}{c}9 \\
24\end{array}$ & $\begin{array}{c}4 \\
49\end{array}$ & 0.013 & $\begin{array}{l}10 \\
34\end{array}$ & $\begin{array}{c}3 \\
39\end{array}$ & $0.044^{*}$ \\
\hline $\begin{array}{l}\text { No. of tumors } \\
\text { Multiple } \\
\text { Single }\end{array}$ & $\begin{array}{c}4 \\
29\end{array}$ & $\begin{array}{c}2 \\
51\end{array}$ & $0.139^{*}$ & $\begin{array}{c}3 \\
41\end{array}$ & $\begin{array}{c}3 \\
39\end{array}$ & $0.953^{*}$ \\
\hline $\begin{array}{l}\text { Vascular inva } \\
\text { Yes } \\
\text { No }\end{array}$ & $\begin{array}{c}9 \\
24\end{array}$ & $\begin{array}{c}4 \\
49\end{array}$ & $0.023^{*}$ & $\begin{array}{c}7 \\
37\end{array}$ & $\begin{array}{c}6 \\
36\end{array}$ & 0.834 \\
\hline $\begin{array}{l}\text { Tumor encaps } \\
\text { Complete } \\
\text { None }\end{array}$ & $\begin{array}{c}8 \\
25\end{array}$ & $\begin{array}{l}27 \\
26\end{array}$ & 0.014 & $\begin{array}{l}12 \\
32\end{array}$ & $\begin{array}{l}23 \\
19\end{array}$ & 0.009 \\
\hline
\end{tabular}

"Fisher's exact tests, and Chi-square tests for all other analyses. For CCN3, and SMA median values were used as cut-off points for definition of subgroups (low expression and high expression groups). TF, tissue factor; OPN, osteopontin; AFP, alpha-fetoprotein; ALT, alanine aminotransferase; HBsAg, hepatitis B surface antigen; HCC, hepatocellular carcinoma.

are positively associated with malignant phenotype and poor prognosis in HCC.

\section{CCN3 enhances migration and proliferation of HSC relating to ERK signaling pathway}

Although peripheral liver tissue with or without cirrhosis can partially affect the OS and CRR of HCC patients, there was no significant difference in OS $(p=$ 0.265 ) and CRR ( $p=0.118$, Figure $4 \mathrm{~A})$. We had proven that the number of HSC in HCC tissues was positively correlated with tumor dimension and OS in HCC patients, and we speculate that HCC-derived chemokines induce HSC transmigration into the tumor tissue, which plays a key role in malignant progression in HCC.
To investigate the roles and mechanism of $\mathrm{CCN} 3$ on $\mathrm{HSC}$, we treated LX2 cells with recombinant $\mathrm{CCN} 3$, which could significantly enhance the migration $(16.75 \pm 3.30$ vs. $39.50 \pm 4.79, p=0.0027$, Figure $4 \mathrm{~B}$ ) and proliferation ( $1.55 \pm 0.11$ vs. $2.11 \pm 0.15, p=0.0021$ ) of LX2 (Figure 4C). Further, we investigate the associated mechanism of CCN3 on LX2, and proved CCN3 led to the activated ERK signaling pathways with upregulation of RAF, p-RAF, p-MEK and p-ERK. On the other hand, LX2 cells treated with sorafenib $(2 \mu \mathrm{mol} / \mathrm{L})$ or MEK1/2 inhibitor U0126 $(10 \mu \mathrm{mol} / \mathrm{L})$ showed significant inhibition on ERK signaling (Figure 4D). To investigate the role of $\mathrm{CCN} 3$ and ERK signaling pathways on the migration and proliferation of LX2, we treated LX2 cells with sorafenib $(2 \mu \mathrm{mol} / \mathrm{L})$ and MEK1/2 inhibitor U0126 $(10 \mu \mathrm{mol} / \mathrm{L})$ again. Sorafenib treatment could significantly 
inhibit the migration $(16.75 \pm 3.30$ vs. $4.75 \pm 2.76, p=0.0023)$ and proliferation $(1.55 \pm 0.11$ vs. $2.11 \pm 0.15, p=0.0021)$ of LX2. To further clarify the role of ERK signaling activated by CCN3 in the migration of LX2, Sorafenib or U0126 combined with CCN3 exhibited decreased migration $(39.50 \pm 3.30$ vs. $13.51 \pm 4.93, p=0.0002 ; 39.50 \pm 3.30$ vs. $19.01 \pm 4.32, p=0.0011)$ and proliferation $(2.18 \pm 0.07 \mathrm{vs}$. $1.45 \pm 0.08, p<0.0001 ; 2.18 \pm 0.07$ vs. $1.57 \pm 0.08, p<0.0001)$ of LX2 with down-regulated ERK signaling (Figure 4C, 4D). In this section, we proved enhanced migration and proliferation of $\mathrm{HSC}$ were relating to ERK signaling pathway after treated by $\mathrm{CCN} 3$.

\section{CCN3 induce the remodeling of HSC with elevation of cytokines relating to $\mathrm{HCC}$ malignancy}

While studying the direct role of $\mathrm{CCN} 3$ on $\mathrm{HSC}$, we treated LX2 with CCN3 and found the significantly up-regulated cytokines expression profiles by cytokines array in LX2-CCN3, with the up-regulated cytokines of RANTES, IL-16, IL-1a, IL-13, IL-2, TNFa, TGF $\beta$, and MCP-1 et al, and down-regulated cytokines of TIMP-1, sTNFRII et al (Figure 5A). Further, RANTES and TGF $\beta$ were selected for immunoblotting and we proved the significant increase of the two cytokines, which were regulated by $\mathrm{NF} \kappa \mathrm{B}$ signaling after we overexpressed CCN3 in LX2. To validate this effect, NFאB signaling was inhibited with concomitant down-regulation of RANTES, TGF $\beta$, and up-regulation of TIMP-2 after treatment with NFкB inhibitor EVP4593 (Figure 5B). To investigate the effect of $\mathrm{NF} \kappa \mathrm{B}$ signaling pathways of $\mathrm{HCC}$ on the migration and proliferation of HSC, we treated HCC cells with NFאB inhibitor EVP4593, and collected the CM. We proved the reduced migration $(35.01 \pm 9.89$ vs. $6.75 \pm 3.50$ $p=0.0238)$ and inhibited proliferation (1.67 \pm 0.75 vs. $1.25 \pm 0.08 p=0.0016)$ of LX2 in the CM from EVP4593

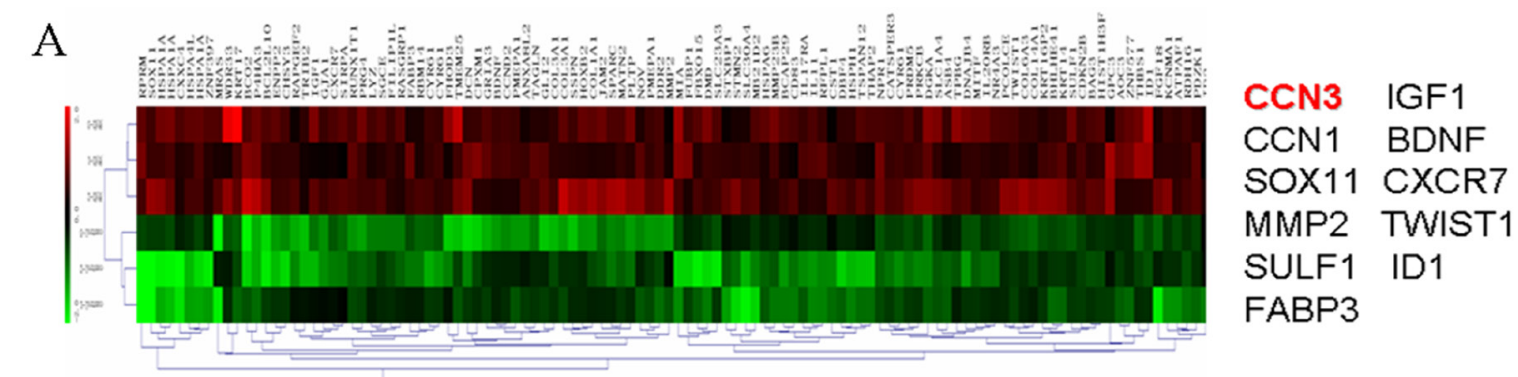

B

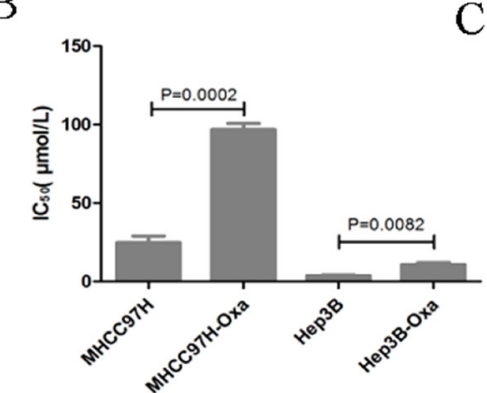

$\mathrm{E}$

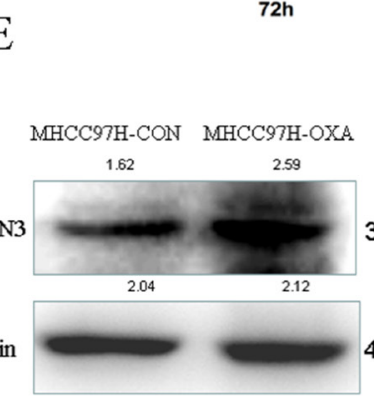

$\mathrm{C}$

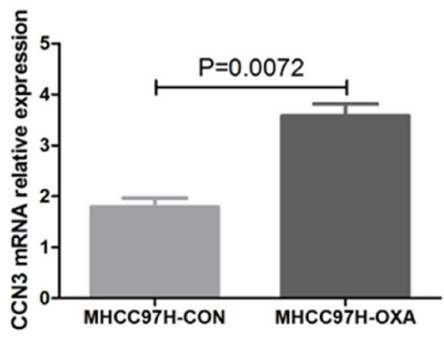

$\mathrm{D}$

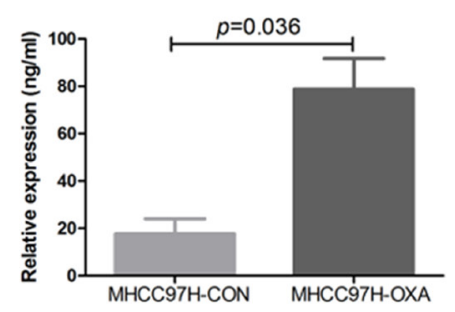

F

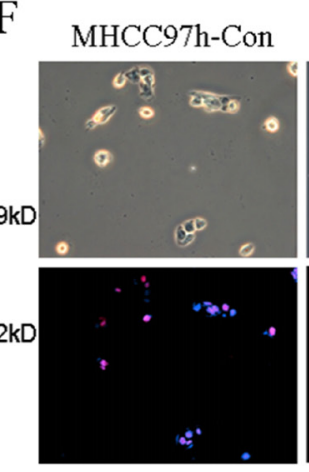

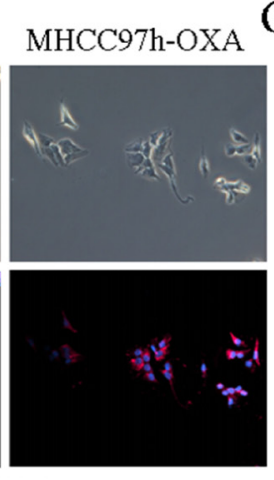

CCN3
G
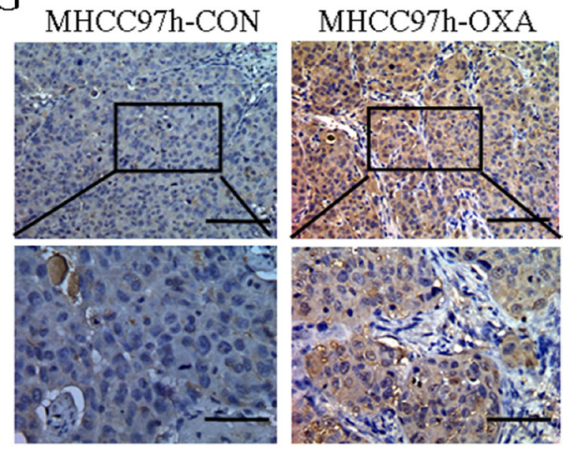

$\mathrm{CCN} 3$

Figure 2: Expression of CCN3 is upregulated in oxaliplatin-resistant $\mathbf{H C C}$. The cDNA profile was reanalyzed and CCN3 was found as one of the significantly upregulated genes (A). The increased resistance to oxaliplatin was in MHCC97H-OXA and Hep3B-OXA over that of parental cells (B). PCR (C), ELISA (D), Immunoblotting (E) and Immunofluorescence (F) revealed that the expression of CCN3 in MHCC97H-OXA cells was significantly higher than that of parental cells. IHC revealed CCN3 expression was significantly upregulated in oxaliplatin-resistant HCC subcutaneous tissue $(\mathbf{G})$. 
A
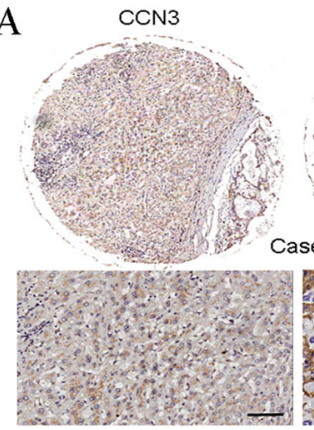

$\mathrm{CCN} 3$

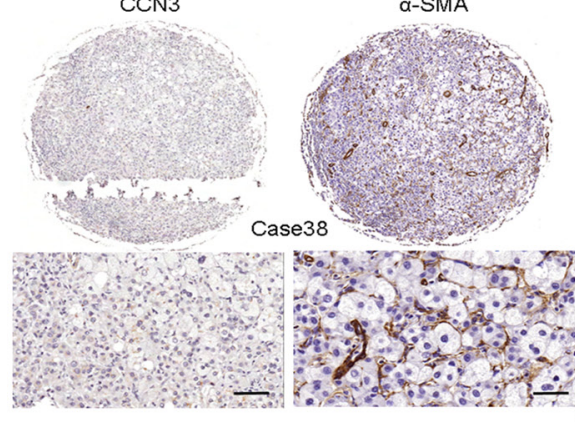

B

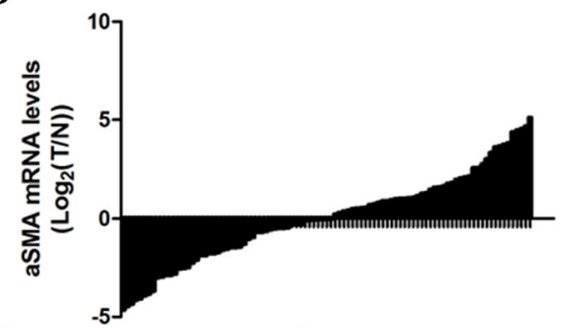

C

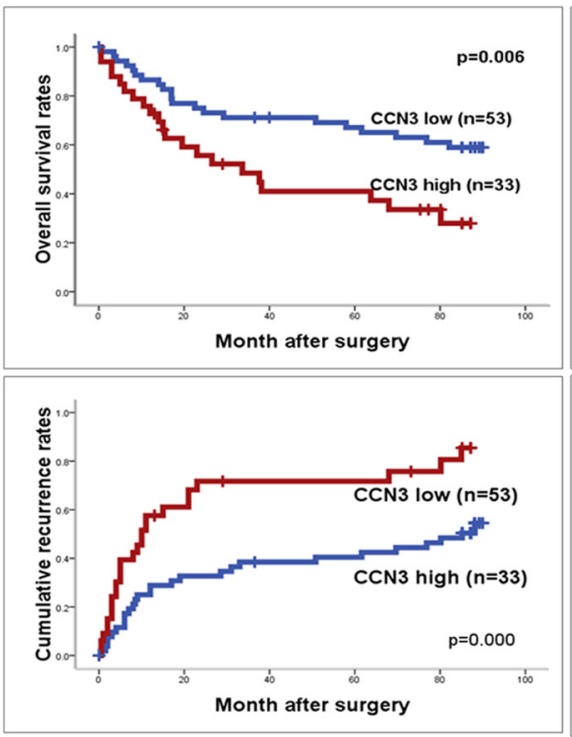

a
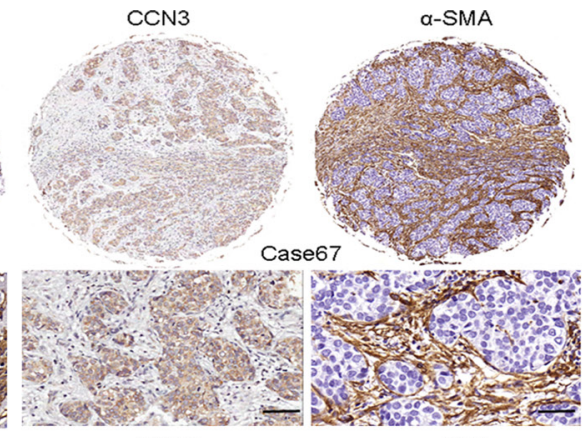

$\mathrm{CCN} 3$
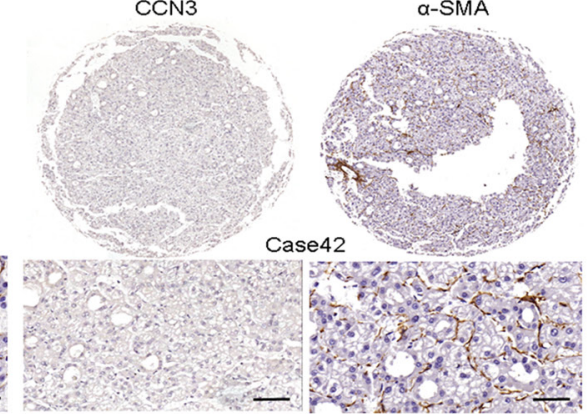

a

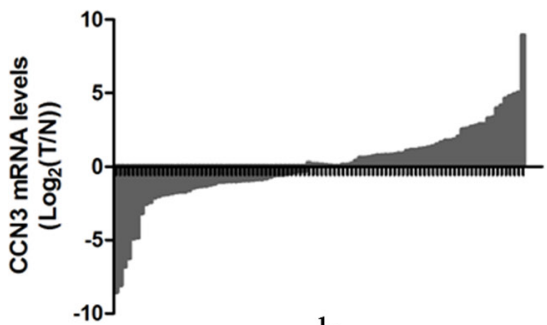

b
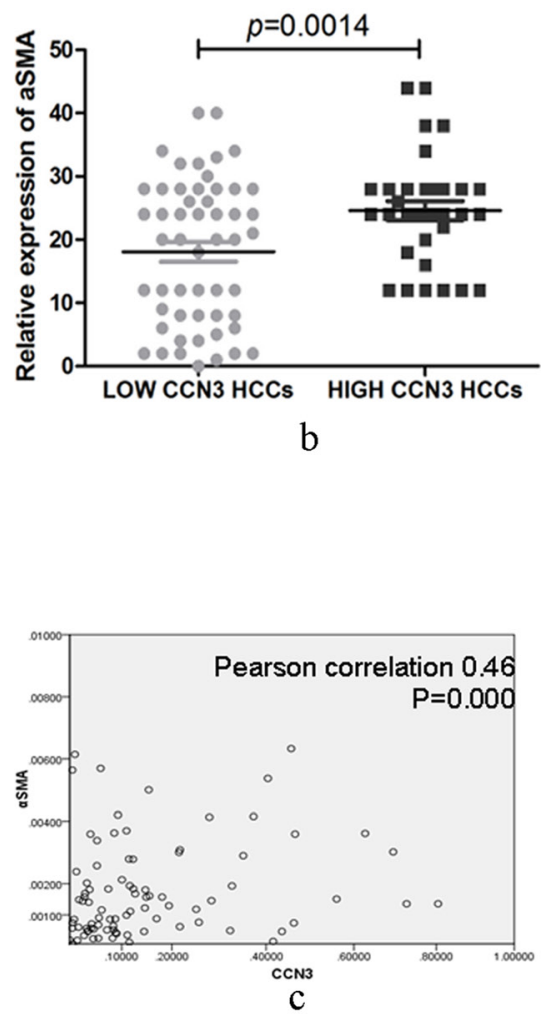

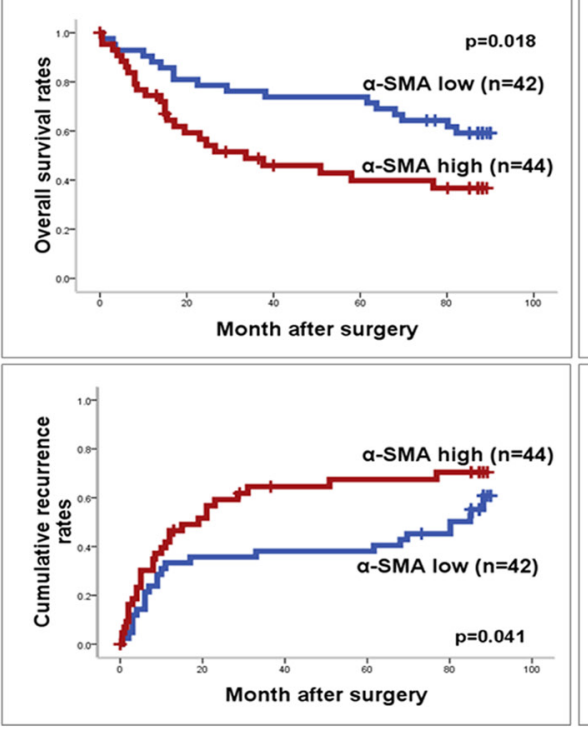

b

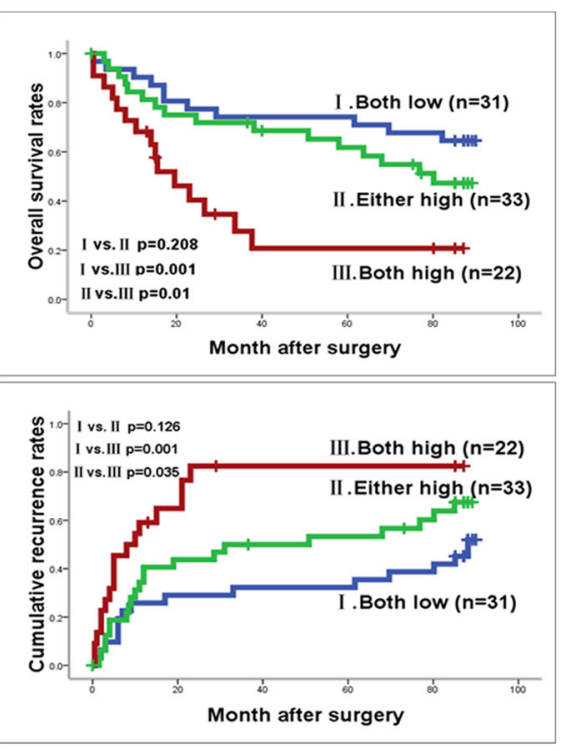

c

Figure 3: High expression of CCN3 and $\alpha$-SMA is the positively associated poor prognosis in HCC. The expression of CCN3 is positively correlated with $\alpha$-SMA ( $(a, \mathbf{A} ; \mathrm{a}, \mathrm{b}, \mathrm{c}, \mathbf{B})$. The expression of $\alpha$-SMA in high CCN3 HCC group was higher than that of $\alpha$-SMA in low CCN3 HCC group (b, A). The patients with high expression of CCN3/ $\alpha$-SMA had significantly lower OS and higher CRR than the patients with low expression of CCN3 $(a, b, C)$. HCC patients were classified into three subgroups based on CCN3 and $\alpha$-SMA expression levels, and patients with high expression of CCN3 and $\alpha$-SMA had the highest CRR and lowest OS (c, C). 
treated HCC (Figure 5C). In this section, we proved CCN3 induce the remodeling of HSC with elevation of cytokines relating to $\mathrm{HCC}$ malignancy.

\section{CCN3 enhanced the infiltration of HSC into HCC and promote the tumor proliferation in the xenograft tumor model}

To investigate the role of $\mathrm{CCN} 3$ in modulating the transmigration of HSC in vivo, we examined the expression of $\alpha$-SMA by immunohistochemistry in the tissue of xenograft tumor model. In nude mouse models, the diminished number of HSC with low expression of $\alpha$-SMA was found in mice injected with MHCC97HCCN3-sh cells, meanwhile, diminished subcutaneous tumor weight in nude mouse models was found in the MHCC-97H-CCN3-sh group $(0.91 \pm 0.19$ vs. $0.37 \pm 0.11$ $p=0.0125$, Figure 6A). The overexpression of CCN3 through lentiviral infection of $\mathrm{MHCC} 97 \mathrm{H}$ cells in mice led to increased number of HSC with high expression of
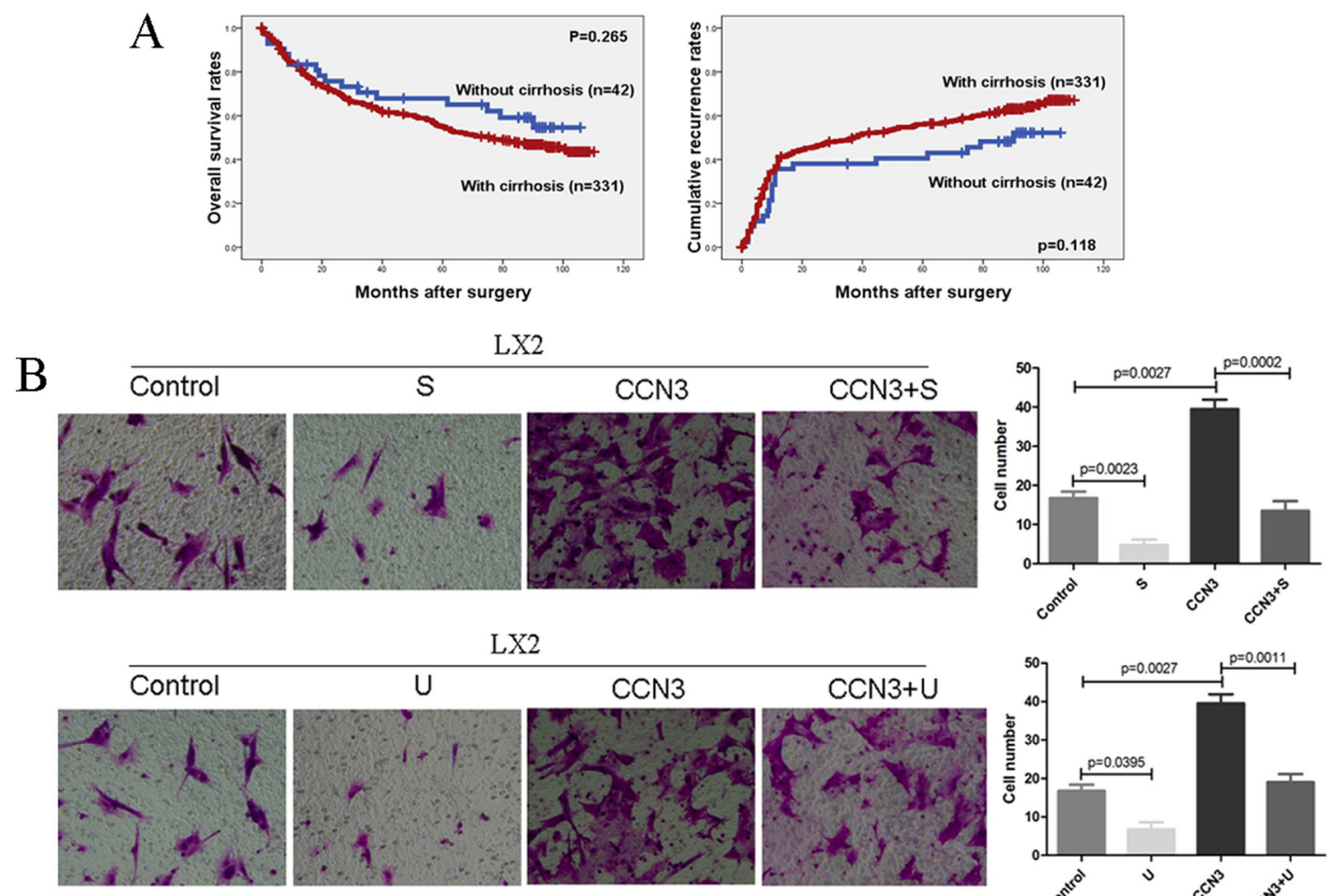

$\mathrm{C}$
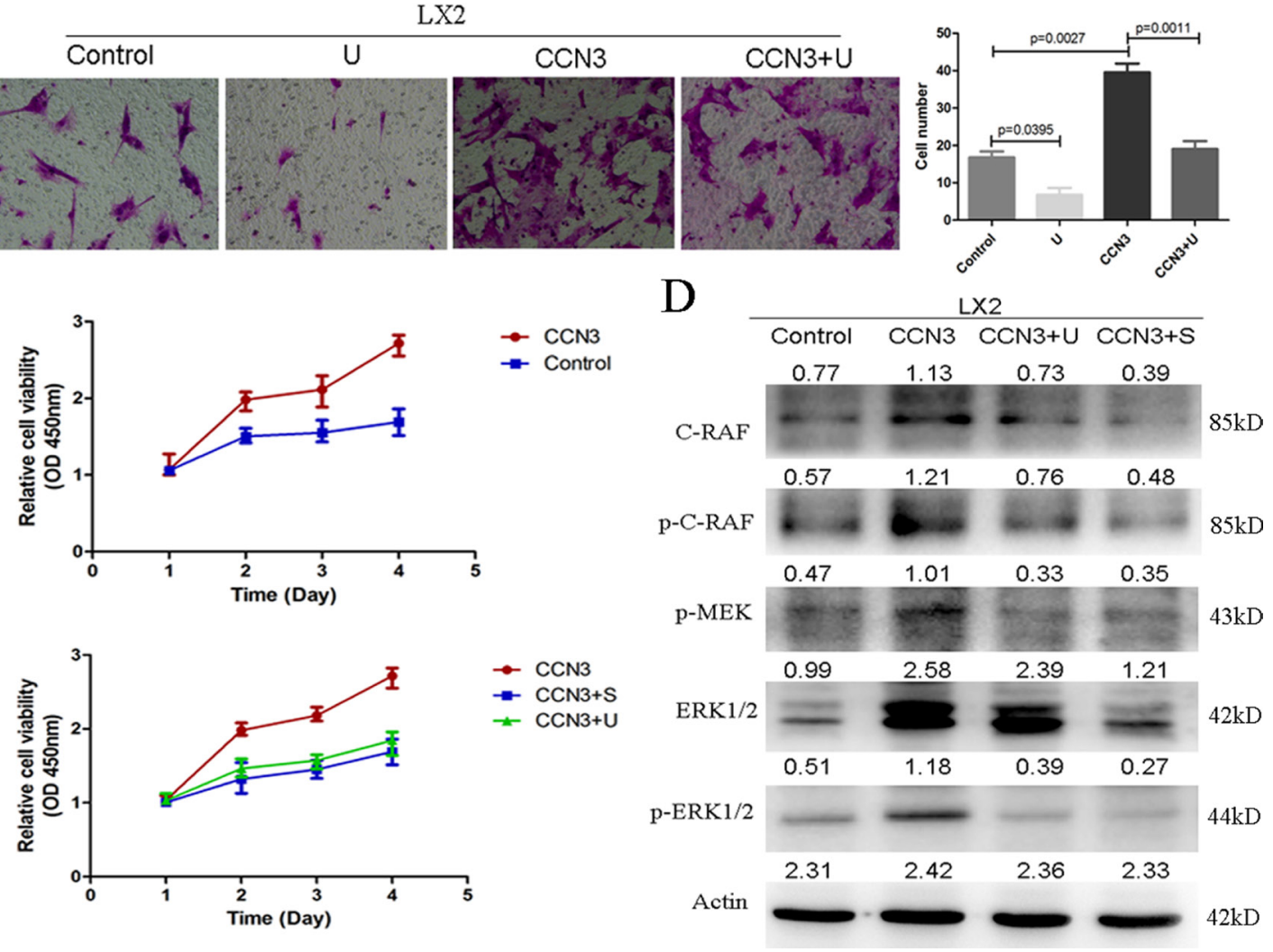

Figure 4: Migration and proliferation ability of HSC is related to CCN3-RAF-ERK signaling. There was no significant difference in OS and CRR between patients with or without cirrhosis (A). Recombinant CCN3 could significantly enhance the migration (B) and proliferation (C) of LX2, which could be reversed by S (sorafenib) or U (U0126). CCN3 could activate ERK signaling pathways with upregulation of RAF, p-RAF, p-MEK and p-ERK, and sorafenib or U0126 showed significant inhibition on ERK signaling (D). 
$\alpha$-SMA, and the enhanced subcutaneous tumor growth was found in the MHCC-97H-CCN3 group $(0.74 \pm 0.30 \mathrm{~g}$ vs. $1.43 \pm 0.19 \mathrm{~g} p=0.0308$, Figure $6 \mathrm{~B}$ ). In this section, we confirmed CCN3 enhanced the infiltration of HSC, and which promoted the tumor proliferation in the xenograft tumor model.

\section{DISCUSSION}

Approximately $90 \%$ of HCC develops in chronically damaged tissue due to liver cirrhosis, and chronic hepatitis $B$ virus infection remains the major risk factor [6]. Cirrhosis is closely affecting the liver function and is strongly associated with the development of HCC [7]. This milieu of fibrosis further reduces the responsiveness of tumor cells towards various clinical treatments, thus directly affecting the tumor malignancy progression [8]. It is believed that focusing upon cirrhosis makes it possible to evaluate $\mathrm{HCC}$ heterogeneity and explore new therapies to move towards a more personalized medical approach.

A previous study has demonstrated that HSCs play a key role in causing liver cirrhosis and infiltration into the HCC milieu [9]. HSCs are well known to be one of the key cell types that contribute to the pathogenesis of cirrhosis,
A

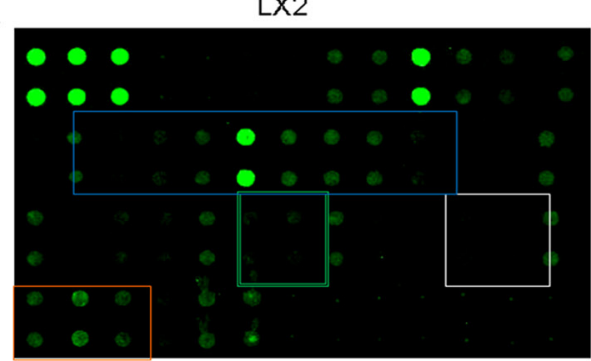

$\mathrm{L} \times 2-\mathrm{CCN} 3$

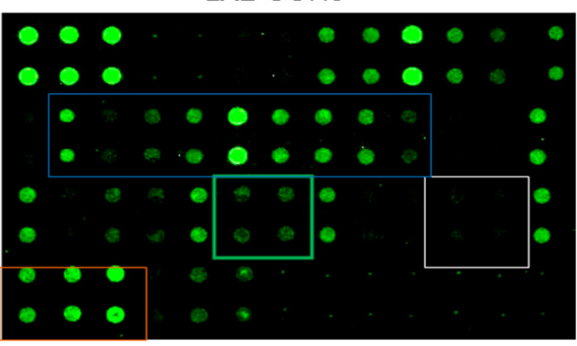

$\mathrm{B} \quad \frac{\mathrm{LX} 2}{\mathrm{WT}} \quad \frac{\mathrm{LXN2}-\mathrm{CCN} 3}{\text { Control EVP4593 }}$

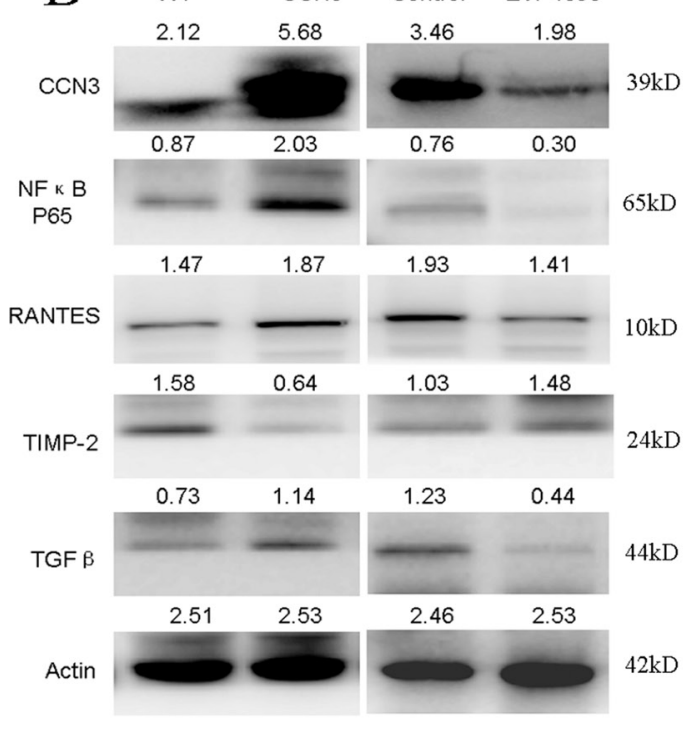

Name LX2 LX2-CCN3 LX2/LX2-CCN3

\begin{tabular}{|c|c|c|c|}
\hline TIMP-2 & 177 & 87 & 2.03 \\
\hline STNF RII & 67 & 34 & 1.93 \\
\hline PDGF-BB & 173 & 100 & 1.72 \\
\hline MIP-1b & 28 & 18 & 1.51 \\
\hline MCP-1 & 188 & 233 & 0.81 \\
\hline IL-6 & 148 & 185 & 0.80 \\
\hline IFN-g & 153 & 192 & 0.79 \\
\hline TGF-b1 & 192 & 243 & 0.79 \\
\hline IL-1b & 18 & 22 & 0.78 \\
\hline IL-15 & 181 & 235 & 0.77 \\
\hline CCL24 & 19 & 25 & 0.75 \\
\hline CSF2 & 152 & 204 & 0.74 \\
\hline TNF-a & 175 & 245 & 0.71 \\
\hline IL-2 & 182 & 268 & 0.68 \\
\hline IL-13 & 167 & 246 & 0.68 \\
\hline sIL-6R & 1579 & 2527 & 0.62 \\
\hline IL-1a & 116 & 194 & 0.59 \\
\hline IL-16 & 16 & 28 & 0.56 \\
\hline IL-12 p40 & 16 & 28 & 0.55 \\
\hline IL-12 p70 & 7 & 21 & 0.31 \\
\hline STNF RI & 162 & 560 & 0.29 \\
\hline RANTES & 7 & 28 & 0.25 \\
\hline & & & \\
\hline
\end{tabular}

C $\mathrm{MHCC} 97 \mathrm{H}-\mathrm{CCN} 3-\quad \mathrm{MHCC} 97 \mathrm{H}-\mathrm{CCN} 3-$ $\mathrm{CON}-\mathrm{CM}$

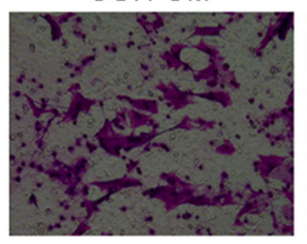
EVP4593-CM
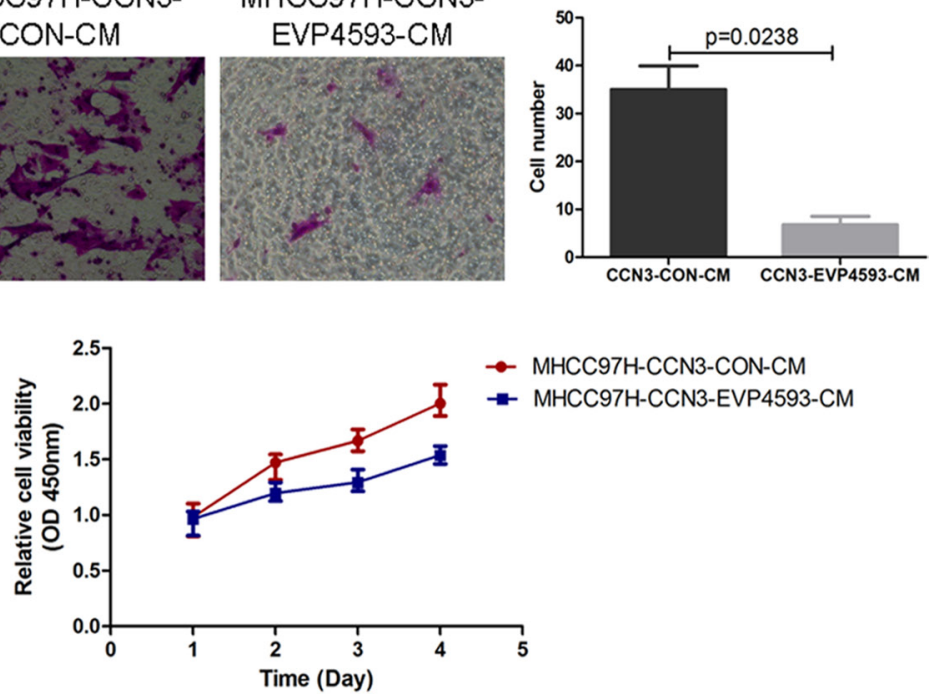

Figure 5: CCN3 induce the remodeling of HSC with elevation of cytokines relating to HCC malignancy. The significantly changed cytokines expression profiles were found in CCN3 treated LX2 by cytokines array (A). RANTES, TGF $\beta$ and TIMP-2 were selected for immunoblotting, and NFאB was proved as one of the control signaling pathway (B). The reduced migration and inhibited proliferation of LX2 were proved in the CM from NFKB inhibitor EVP4593 treated MHCC97H (C). 
which are activated in response to liver damage and trans-differentiate into mesenchymal fibroblasts (MFs), and play a key role in aggravating hepatic fibrosis to the form of waterfall effect [10]. It is reported that peripheral liver tissue with cirrhosis can affect the progression of HCC patients [11], while in the present study, we proved there was no significant effect of cirrhosis on OS and CRR of HCC patients, and we speculate HSCs transmigrating into $\mathrm{HCC}$ tissue are the key to promote HCC malignant progression. It is known that HSCs can infiltrate into the stroma of liver tumors, where they are remodeled as cancer associated fibroblasts (CAFs) and play a critical role in HCC progression [8]. To explore the mechanism of oxaliplatin resistance from the perspective of HCC microenvironment, in the present study, we proved increased accumulation of HSCs with fibrous connective tissue and collagen in oxaliplatin-resistant HCC tissue milieu. In HCC patients, we also proved the expression of $\alpha$-SMA representing the number of HSCs was significantly associated with malignant phenotype, and the patients with high $\alpha$-SMA expression in HCC tissue had poor prognosis. Previously, we constructed oxaliplatin-resistant HCC models and found the CCN family was significantly changed in oxaliplatin-resistant HCC. And the paracrine of CCN3 from HCC was one of the significantly up-regulated protein in $\mathrm{HCC}$, especially in oxaliplatin-resistant HCC [4].

The CCN family, first described by P. Bork in 1993, is a small, six-member family of cysteine-rich regulatory proteins found in humans. Members of this secreted protein family comprise a secretory signal peptide followed by four structural domains; namely, insulin-like growth factor binding proteins (IGFBP), von Willebrand factor type C repeat (VWC), thrombospondin type I repeat (TSP-1), and carboxy-terminal domain (CT) [3]. Because the four unique globular modules share homology with functional domains of various extracellular proteins, $\mathrm{CCN}$ proteins have emerged as localized multitasking signal integrators in the inflammatory microenvironment [12]. Many studies have shown how physiological and pathological events acting on each catalytic domain of CCNs affect differentiation [13], adhesion [14], migration [15], mitogenesis [16], chemotaxis

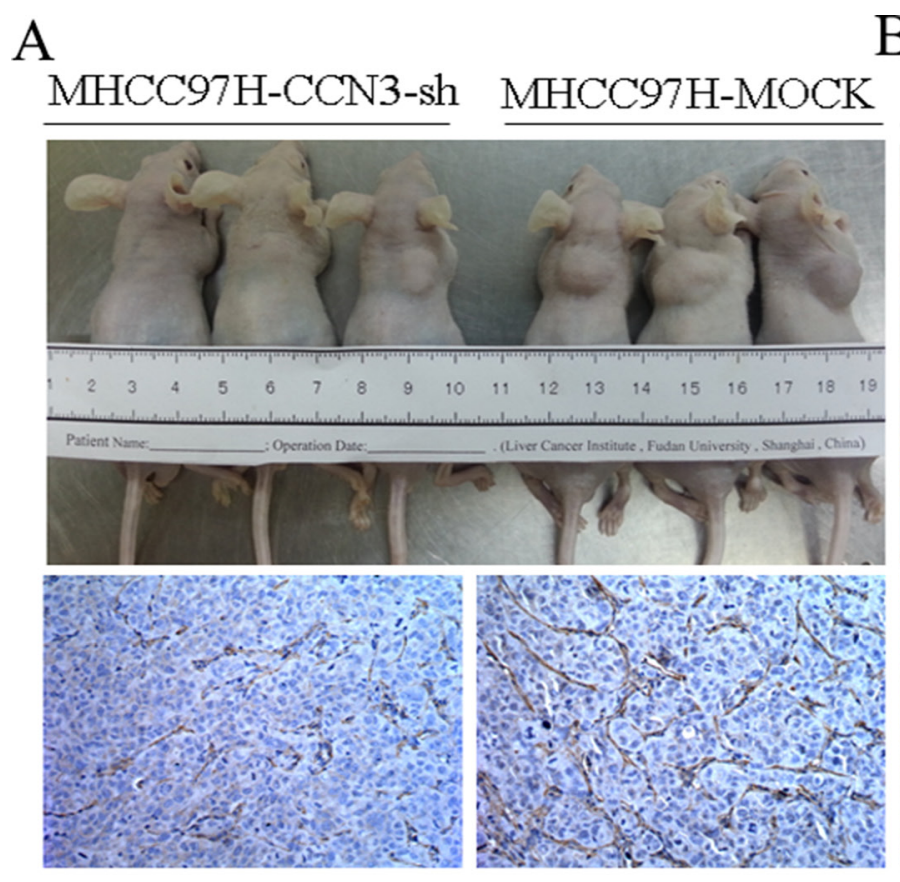

$\mathrm{B}$
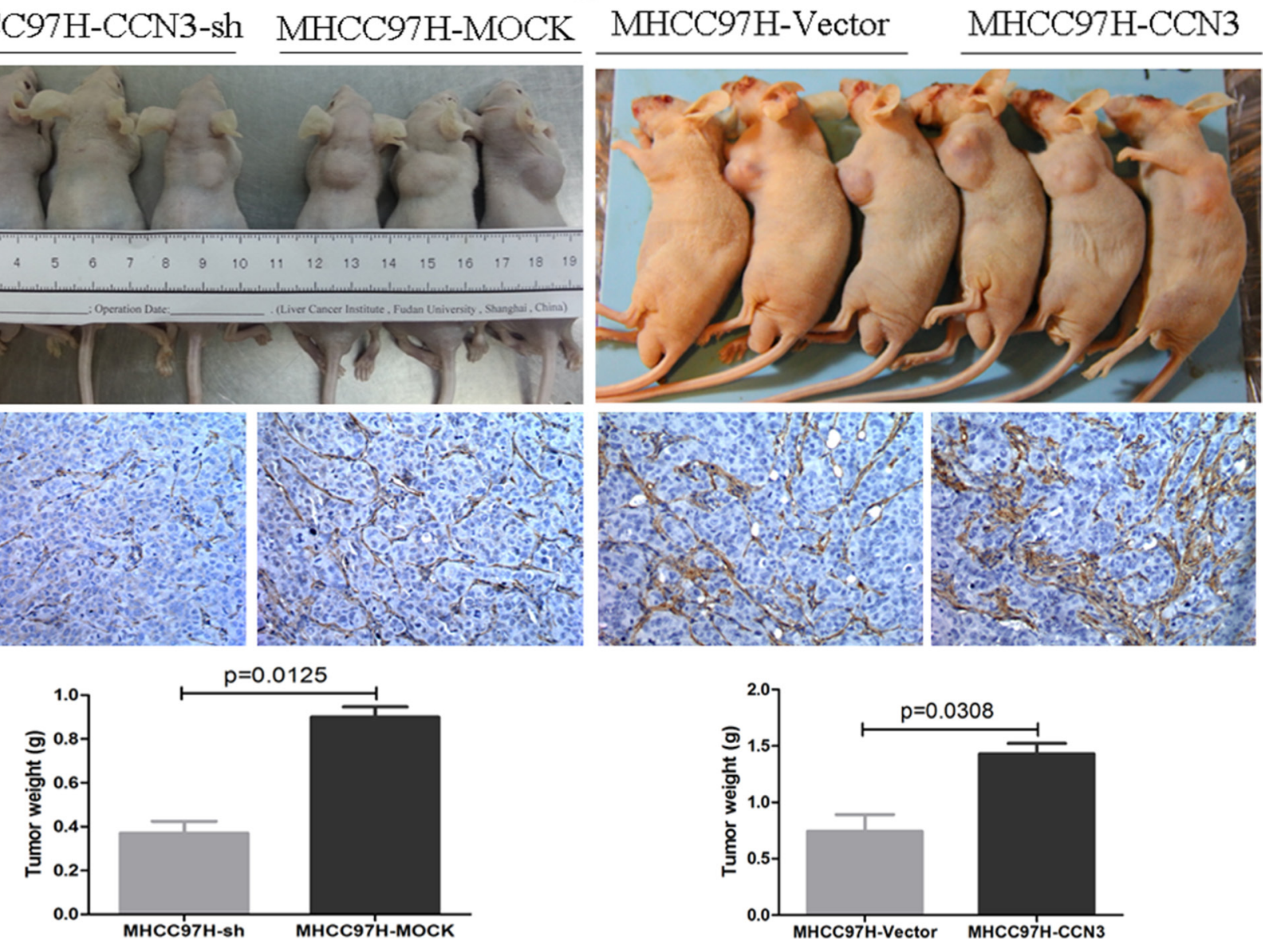

Figure 6: CCN3 enhanced the infiltration of HSC into HCC and promoted the tumor proliferation in the xenograft tumor model. The diminished number of HSC and subcutaneous tumor weight were found in mice injected with $\mathrm{MHCC} 97 \mathrm{H}-\mathrm{CCN} 3-\mathrm{sh}$ cells in nude mouse models (A). The increased number of HSC and the enhanced subcutaneous tumor growth were found in the MHCC97H-CCN3 group (B). 
[17] and angiogenesis [18]. Recently, interest in CCN3 has emerged for cancer research because of the protein's central roles in cell regulation $[3,19]$. Chen $[20,21]$ et al has shown that prostate cancer-derived CCN3 can induce M2 macrophage infiltration, relating to the construction of the prospective environment conducive to prostate cancer metastasis. Previously, we had reported that HSCs could interact with hepatoma cells via secretion of cytokines, which play a critical role in modulating the malignant phenotypic changes of HCC [22, 23]. In the present study, we proved the infiltration of HSCs into the $\mathrm{HCC}$ milieu relating to $\mathrm{CCN} 3$ paracrine of $\mathrm{HCC}$, and $\mathrm{CCN} 3$ could elevate the cytokines paracrined by HSCs relating to enhanced HCC malignancy, all of which indicate the important role of CCN3 in the crosstalk between HCC and HSCs.

Cancer cells do not manifest the disease alone and the stroma is inappropriately activated in cancer to contribute to malignant characteristics of tumor cells. The stroma and the tumor cells always create a complex system with reciprocal signaling [24].Uncontrolled or sustained damage of liver tissue with the activation and infiltration HSC is now recognized as a hallmark feature of HCC development and metastasis [25]. Accumulating evidence supports the concept that activated HSCs are the main matrix-producing cells in the process of liver fibrosis, resulting in ECM accumulation and HCC progression [26, 27]. The functions of $\mathrm{CCN}$ family proteins are involved in the regulations of HCC microenvironment [28]. It has been reported the enhanced expression of CCN3 was found in HCC samples when compared to levels in matched non-cancerous tissues, and these results suggest that $\mathrm{CCN} 3$ was associated with the development of tumors $[29,30]$. In the present study, we proved the expression of $\mathrm{CCN} 3$ is up-regulated in oxaliplatinresistant $\mathrm{HCC}$, which induced the remodeling of HSCs with elevation of cytokines such as RANTES, IL-16, IL-1a, IL13, IL-2, TNFa, TGF $\beta$, and MCP-1 et al, resulting in the maintenance of oxalipaltin-resistance of HCC. This may in part reflect the abnormal HCC microenvironment, which acts to support the growth and chemoresistance of $\mathrm{HCC}$

Currently, drug development in HCC remains focusing on HCC itself, which could be ignorance of the importance of the HCC microenvironment driving a tumor-permissive milieu. Throughout the process of HCC progression, tumor cells constantly communicate with the fibrotic microenvironment and improve their malignant potential. Now we proved that CCN3 is recognized as a hallmark of HCC development and chemo-resistance, and better therapies will hopefully follow the thorough understanding of the biological functions of $\mathrm{CCN} 3$ protein.

\section{MATERIALS AND METHODS}

\section{Patients and follow-up}

For this study, 86 paired HCC samples were used for immunohistochemistry. The samples were obtained with informed consent from patients who underwent curative resection between January 2004 and December 2006 at the Liver Cancer Institute and Zhongshan Hospital of Fudan University. Curative resection was defined as the complete resection of tumor nodules, leaving the tumor margins free of cancer upon histologic examination. Histopathologic diagnosis was performed according to the WHO criteria. Patients were followed-up after the surgical treatment until December 2013. The median follow-up period was 63 months (range, $0-110$ months). The clinicopathologic characteristics of all HCC patients in this study are provided in Table 1. Another $98 \mathrm{HCC}$ samples were used for real-time polymerase chain reaction (PCR) analysis for evaluating the relationship of $\mathrm{CCN} 3$ and $\alpha$-SMA in mRNA level, and $373 \mathrm{HCC}$ patients with or without cirrhosis were used for survival statistical analysis. Histopathologic diagnosis was performed according to the WHO criteria.

\section{Vector construction, transfection, and lentivirus transduction}

Human full-length CCN3 cDNA (NM_002165) was obtained from GeneCards (Shanghai, China) and cloned into the pCDH lentiviral expression vector (System Biosciences, CA, USA). The amplified fragment was inserted into the pCDH plasmid (between $\mathrm{XbaI}$ and EcoRI sites) by using the In-Fusion ${ }^{\circledR}$ HD Cloning Kit (Takara, Tokyo, Japan). The target sequences of lentiviral shRNA expression plasmids PLKO.1 are as follows: CCCACCATCAAAGGAATATAA (Sh1), CGCACCAAGAAGTCACTCAAA (Sh2), and CACCAATAGGAACCGTCAATG (Sh3).

\section{Cell lines and animals}

We used human HCC cell lines MHCC97H (established at Fudan University), Hep3B, and hepatic stellate cell lines LX2 (American Type Culture Collection). All cells were maintained in Dulbecco's Modified Eagle's Medium (DMEM; GICBO, Grand Island, NY), supplemented with $10 \%$ fetal bovine serum (FBS; GICBO) at $37^{\circ} \mathrm{C}$ in a humidified incubator with $5 \% \mathrm{CO}_{2}$. Cells were routinely screened for the presence of mycoplasma (Mycoplasma Detection Kit, Roche Diagnostics).

Male BALB/c nu/nu mice (aged 4-6 weeks and weighing approximately $20 \mathrm{~g}$ ) were obtained from the Chinese Academy of Science (SLRC, Shanghai, China) and maintained under standard pathogen-free conditions. To produce tumors, we performed subcutaneous injections of HCC-97H-CCN3-sh and HCC-97H-Mock into the upper right flank region of the mice. HCC-97H-CCN3 and HCC-97H-Vector cells were injected into the upper left flank region of male BALB/c nu/nu mice. Animals were sacrificed five weeks after injections. The study protocol was approved by the Shanghai Medical Experimental Animal Care Commission. 


\section{RNA extraction and qRT-PCR}

Total RNA was extracted from HCC cells using TRIzol ${ }^{\mathbb{R}}$ reagent (Invitrogen, Carlsbad, CA, USA). The primers used for the amplification of human genes are the following: $\mathrm{CCN} 3$, 5'-CACGGCGGTAGAGGGAGATAA-3' (forward) and 5'-TGGGCCACAGATCCACTTTTC-3' (reverse); $\alpha$-SMA, 5'-TCCCTTGAGAAGAGTTACGAGTT-3' (forward) and 5'-CATGATGCTGTTGTAGGTGGTT-3' (reverse).

\section{Cell migration ability assays}

LX2 cells were cultured in different conditioned media, and cell migration was performed as previously described [22], (Boyden chambers, Corning, Flintshire, UK) using the Conditioned Medium (CM) of MHCC97H-Con-CM, and MHCC97H-Oxa-CM. Then, $5 \times 10^{4}$ cells in serum free DMEM were seeded into the upper chamber of each well on the membrane $(8.0 \mu \mathrm{m}$ pore size) of a 24 -well plate. $\mathrm{CM}$ was added to the lower chamber of each well. After $48 \mathrm{hrs}$, cells reaching the underside of the membrane were stained with Giemsa (Sigma-Aldrich) and counted at $\times 200$ magnification.

\section{Immunohistochemistry, immunofluorescence, immunoblotting and ELISA assays}

Immunohistochemistry, Immunofluorescence, Immunoblotting and ELISA were performed as previously described [31]. The BCA Protein Assay Kit (Beyotime, Shanghai, China) was used to determine the concentration of extracted protein. Levels of CCN3 in the cultured supernatants were quantified by ELISA kits (R\&D Lab Inc., Minneapolis, MN, USA). MEK1/2 inhibitor U0126, NFKB inhibitor EVP4593, and Sorafenib were obtained from Selleckchem (Houston, TX, USA). Primary antibodies used for immunofluorescence, immunoblotting and/or, immunohistochemistry were as follows: $\mathrm{CCN} 3$, $\alpha$-SMA, p-C-RAF, ERK1/2, NFkB, TIMP-2, TGF- $\beta$, and p-ERK1/2 (Abcam, Cambridge, MA, USA), RANTES and C-RAF (Cell Signaling, Beverly, MA, USA), p-MEK (Epitomics, Burlingame, CA, USA), Actin (Jackson Labs, Bar Harbor, ME, USA).

\section{Cytokines antibody array}

Cytokines microarrays were used to evaluate the changes in cytokine expression profiles of LX2 after $\mathrm{CCN} 3$ treatment. Total RNA extracted from $\mathrm{CCN} 3$ treated with LX2 and control cells were used for Cytokines antibody array analysis. Microarray analysis of three independent samples was performed according to the manufacturer's instructions.

\section{Statistical analysis}

Kaplan-Meier analysis was performed to compare CRR and OS between patients in different groups and statistic, and the values were generated by the CoxMantel log-rank test. Quantitative differences in the data on tumor volume, gene and protein expression levels, and cell number were evaluated by $t$-test. Statistical analyses were performed using SPSS 15.0 for Windows (SPSS) as previously described [32]. A $p$-value of less than 0.05 was considered statistically significant.

\section{Abbreviations}

HCC, hepatocellular carcinoma; HSCs, hepatic stellate cells; HBV, hepatitis B virus; NOV, nephroblastoma overexpressed proteins; OS, overall survival rates; CRR, cumulative recurrence rates; CM, conditioned medium; CAFs, cancer associated fibroblasts; $\mathrm{PCR}$, polymerase chain reaction; DMEM, dulbecco's modified eagle's medium.

\section{Author contributions}

RTW, WC, ZW, QBZ, YB, SNY contributed to the study design, analysis, and interpretation of data. QAJ conceived the study. RTW, ZW, and WC performed the majority of the experiments. QBZ, and YB participated in the establishment of the nude mouse model. SNY participated in statistical analysis. QAJ drafted and prepared the manuscript. All authors approved the final manuscript.

\section{CONFLICTS OF INTEREST}

The authors declare that they have no competing interests.

\section{FUNDING}

This research project was supported by the National Natural Science Foundation of China (81502694), Postdoctoral Science Foundation of China (2015M570330).

\section{REFERENCES}

1. Torre LA, Bray F, Siegel RL, Ferlay J, Lortet-Tieulent J, Jemal A. Global cancer statistics, 2012. CA Cancer J Clin. 2015; 65:87-108.

2. Thompson AI, Conroy KP, Henderson NC. Hepatic stellate cells: central modulators of hepatic carcinogenesis. BMC Gastroenterol. 2015; 15:63.

3. Jia Q, Dong Q, Qin L. CCN: core regulatory proteins in the microenvironment that affect the metastasis of hepatocellular carcinoma? Oncotarget. 2016; 7:1203-14. https://doi.org/10.18632/oncotarget.6209.

4. Bu Y, Jia QA, Ren ZG, Zhang JB, Jiang XM, Liang L, Xue TC, Zhang QB, Wang YH, Zhang L, Xie XY, Tang ZY. Maintenance of stemness in oxaliplatin-resistant 
hepatocellular carcinoma is associated with increased autocrine of IGF1. PLoS One. 2014; 9:e89686.

5. Li J, Ye L, Owen S, Weeks HP, Zhang Z, Jiang WG. Emerging role of CCN family proteins in tumorigenesis and cancer metastasis (Review). Int J Mol Med. 2015; 36:1451-63.

6. Schlaeger C, Longerich $\mathrm{T}$, Schiller C, Bewerunge P, Mehrabi A, Toedt G, Kleeff J, Ehemann V, Eils R, Lichter P, Schirmacher P, Radlwimmer B. Etiology-dependent molecular mechanisms in human hepatocarcinogenesis. Hepatology. 2008; 47:511-20.

7. Fattovich G, Stroffolini T, Zagni I, Donato F. Hepatocellular carcinoma in cirrhosis: incidence and risk factors. Gastroenterology. 2004; 127:S35-50.

8. Carloni V, Luong TV, Rombouts K. Hepatic stellate cells and extracellular matrix in hepatocellular carcinoma: more complicated than ever. Liver Int. 2014; 34:834-43.

9. Neaud V, Faouzi S, Guirouilh J, Le Bail B, Balabaud C, Bioulac-Sage P, Rosenbaum J. Human hepatic myofibroblasts increase invasiveness of hepatocellular carcinoma cells: evidence for a role of hepatocyte growth factor. Hepatology. 1997; 26:1458-66.

10. Rasanen K, Vaheri A. Activation of fibroblasts in cancer stroma. Exp Cell Res. 2010; 316:2713-22.

11. Zhang DY, Friedman SL. Fibrosis-dependent mechanisms of hepatocarcinogenesis. Hepatology. 2012; 56:769-75.

12. Holbourn KP, Acharya KR, Perbal B. The CCN family of proteins: structure-function relationships. Trends Biochem Sci. 2008; 33:461-73.

13. Nishida T, Kubota S, Aoyama E, Janune D, Lyons KM, Takigawa M. CCN family protein 2 (CCN2) promotes the early differentiation, but inhibits the terminal differentiation of skeletal myoblasts. J Biochem. 2014.

14. Chen YL, Abraham DJ, Xu SW, Pearson JD, Black CM, Lyons KM, Leask A. CCN2 (connective tissue growth factor) promotes fibroblast adhesion to fibronectin. Molecular Biology of the Cell. 2004; 15:5635-46.

15. Cui L, Xie R, Dang S, Zhang Q, Mao S, Chen J, Qu J, Zhang J. NOV promoted the growth and migration of pancreatic cancer cells. Tumour Biol. 2014; 35:3195-201.

16. Weiskirchen R. CCN proteins in normal and injured liver. Front Biosci (Landmark Ed). 2011; 16:1939-61.

17. Ouellet V, Tiedemann K, Mourskaia A, Fong JE, TranThanh D, Amir E, Clemons M, Perbal B, Komarova SV, Siegel PM. CCN3 impairs osteoblast and stimulates osteoclast differentiation to favor breast cancer metastasis to bone. American Journal of Pathology. 2011; 178:2377-88.

18. Chuang JY, Chen PC, Tsao CW, Chang AC, Lein MY, Lin CC, Wang SW, Lin CW, Tang CH. WISP-1 a novel angiogenic regulator of the $\mathrm{CCN}$ family promotes oral squamous cell carcinoma angiogenesis through VEGF-A expression. Oncotarget. 2015; 6:4239-52. https://doi. org/10.18632/oncotarget.2978.

19. Jun JI, Lau LF. Taking aim at the extracellular matrix: CCN proteins as emerging therapeutic targets. Nature Reviews Drug Discovery. 2011; 10:945-63.
20. Chen PC, Cheng HC, Wang J, Wang SW, Tai HC, Lin $\mathrm{CW}$, Tang $\mathrm{CH}$. Prostate cancer-derived CCN3 induces M2 macrophage infiltration and contributes to angiogenesis in prostate cancer microenvironment. Oncotarget. 2014; 5:1595-608. https://doi.org/10.18632/oncotarget.1570.

21. Chen PC, Cheng HC, Tang CH. CCN3 promotes prostate cancer bone metastasis by modulating the tumor-bone microenvironment through RANKL-dependent pathway. Carcinogenesis. 2013; 34:1669-79.

22. Jia QA, Wang ZM, Ren ZG, Bu Y, Xie XY, Wang YH, Zhang L, Zhang QB, Xue TC, Deng LF, Tang ZY. Herbal compound "Songyou Yin" attenuates hepatoma cell invasiveness and metastasis through downregulation of cytokines secreted by activated hepatic stellate cells. BMC Complement Altern Med. 2013; 13:89.

23. Bu Y, Jia QA, Ren ZG, Xue TC, Zhang QB, Zhang KZ, You Y, Tian H, Qin LX, Tang ZY. The herbal compound Songyou Yin (SYY) inhibits hepatocellular carcinoma growth and improves survival in models of chronic fibrosis via paracrine inhibition of activated hepatic stellate cells. Oncotarget. 2015; 6:40068-80. https://doi.org/10.18632/ oncotarget.5313.

24. Giannelli G, Rani B, Dituri F, Cao Y, Palasciano G. Moving towards personalised therapy in patients with hepatocellular carcinoma: the role of the microenvironment. Gut. 2014; 63:1668-76.

25. Diakos CI, Charles KA, McMillan DC, Clarke SJ. Cancerrelated inflammation and treatment effectiveness. Lancet Oncol. 2014; 15:e493-503.

26. Iredale JP, Bataller R. Identifying molecular factors that contribute to resolution of liver fibrosis. Gastroenterology. 2014; 146:1160-4.

27. Scoazec JY, Verrecchia F, Jacob MP, Bruneval P. [Cellular and molecular mechanisms of fibrosis]. [Article in French]. Ann Pathol. 2006; 26:1S43-50.

28. Kular L, Pakradouni J, Kitabgi P, Laurent M, Martinerie C. The CCN family: a new class of inflammation modulators? Biochimie. 2011; 93:377-88.

29. Zhang H, Li W, Huang P, Lin L, Ye H, Lin D, Koeffler HP, Wang J, Yin D. Expression of CCN family members correlates with the clinical features of hepatocellular carcinoma. Oncol Rep. 2015; 33:1481-92.

30. Hirasaki S, Koide N, Ujike K, Shinji T, Tsuji T. Expression of Nov, CYR61 and CTGF genes in human hepatocellular carcinoma. Hepatol Res. 2001; 19:294-305.

31. Jia QA, Ren ZG, Bu Y, Wang ZM, Zhang QB, Liang L, Jiang XM, Tang ZY. Herbal Compound "Songyou Yin" Renders Hepatocellular Carcinoma Sensitive to Oxaliplatin through Inhibition of Stemness. Evid Based Complement Alternat Med. 2012; 2012:908601.

32. Ke AW, Shi GM, Zhou J, Wu FZ, Ding ZB, Hu MY, Xu Y, Song ZJ, Wang ZJ, Wu JC, Bai DS, Li JC, Liu KD, et al. Role of overexpression of CD151 and/or c-Met in predicting prognosis of hepatocellular carcinoma. Hepatology. 2009; 49:491-503. 